\title{
Implementation of Damage Calculation in a Numerical Wheel-rail Contact Simulation \\ C. Buzzi ${ }^{1, *}$, A. Dutzler ${ }^{1}$ and M. Leitner ${ }^{1}$ \\ ${ }^{1}$ Institute of Structural Durability and Railway Technology, Graz University of Technology, Inffeldgasse 25D, 8010 Graz, Austria \\ *corresponding author: christian.buzzi@tugraz.at
}

\section{ABSTRACT}

Railways can transport cargo and persons into a great distance. The combination of high axle loads and the rigid wheels and rails has resulted the steel to encounter high stresses at the wheel-rail contact. These high stresses cause rolling contact fatigue. To prevent and forecast the rolling contact fatigue, the knowledge of stresses and their effect on the local damage is important. One possible way to achieve the result of stresses is based on a finite element analysis. The calculation of rolling contact fatigue is conducted subsequently. This paper presents one possibility to implement damage calculation into a finite element software which uses the post-processing to enable a fast assessment of rolling contact fatigue on the surface and the adjacent volume of a rail.

Keywords: RCF, FEA, wheel-rail contact, elastic-plastic material

\section{Nomenclature}

$\begin{array}{ll}D & \text { Damage } \\ N, n & \text { Number of load-cycles } \\ \mu & \text { Friction coefficient } \\ Q & \text { Vertical force } \\ Y & \text { Transverse force } \\ \sigma & \text { Stress } \\ \varepsilon & \text { Strain } \\ s & \text { Transmission slip }\end{array}$

\section{Abbreviations}

$\begin{array}{ll}R C F & \text { Rolling contact fatigue } \\ F E A & \text { Finite element analysis } \\ U M L & \text { Uniform material law }\end{array}$

\subsection{INTRODUCTION}

An advantage of the railway is the possibility to transport heavy loads overland. In Austria, the axle load of a wagon is limited to 22.5t [1]. This load is carried by the train wheels which are rolling on the rails. The axle load in combination with dynamic forces during the service leads to high stresses in the contact patch between the wheel and rail. Knowledge of the strains and stresses is important. The resultant rolling contact fatigue (RCF) is one of the reasons of damage at railway rails [2-3].

It is difficult to measure stresses under real load which is directly in the contact area between the wheel and rail. Therefore, the determination of stresses via numerical analysis is preferably applied [4-6]. With the data obtained from the simulation, different methods can be used to assess the damage [7-8]. In the present paper, a possibility is presented on how to directly use the results of a finite element analysis into a classical linear damage accumulation and how to evaluate the result in postprocessing.

\subsection{METHODOLOGY}

First, a simple overview of the finite element analysis (FEA) model is shown including the software used for the simulation, the boundary conditions, and some details about the simulation model. The second part deals with the implementation of fatigue calculation. 


\subsection{Finite element model}

The pre- and post-processing and the solving process are made with Marc Mentat 2018 from the MSC Software Corporation.

To achieve a proper dimension of the contact patch between the wheel and rail, a 3D finite element model is used. The whole model is meshed into hexahedral elements with eight nodes (hex8) to keep the solving time short. Figure 1 shows the overall model of a wheel and rail with the vertical force $Q$ and horizontal force Y. To reduce the solver time, a sub model of the wheel and rail is used (see Figure 2). The finite element mesh as shown in Figure 2 exhibits an element edge length of about 3mm. In accordance with [10], a typical maximum axle load of a high-speed train is about $200 \mathrm{kN}$; hence, the vertical force $\mathrm{Q}$ for one wheel is defined at $100 \mathrm{kN}$. The horizontal force $\mathrm{Y}$ is determined at $20 \mathrm{kN}$ (see Figure 3).

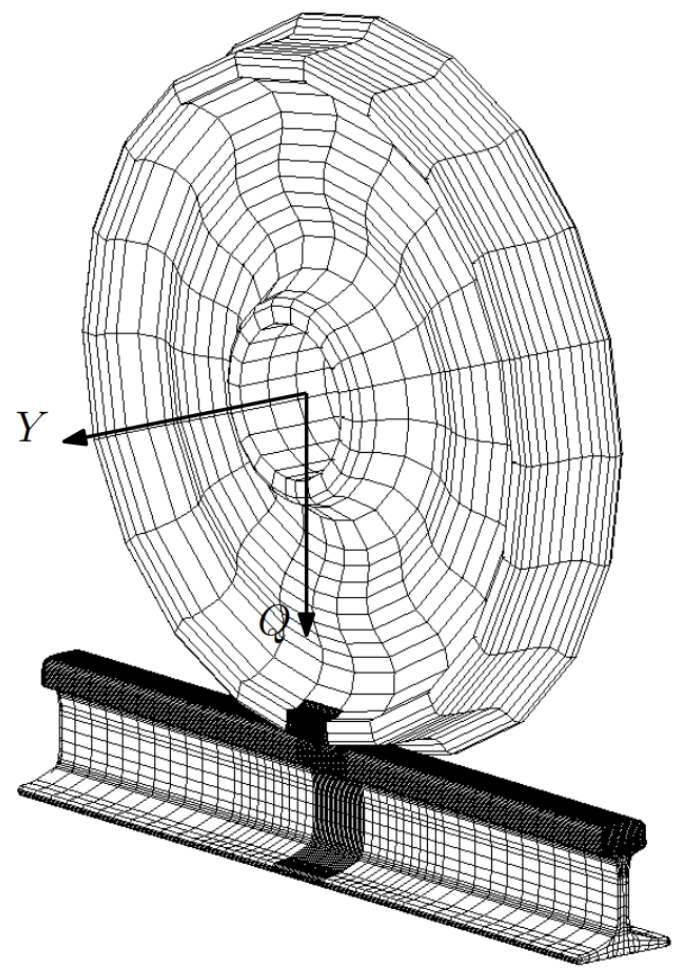

Figure 1. Overall model of a train wheel and rail with the forces $\mathrm{Q}$ and $\mathrm{Y}$

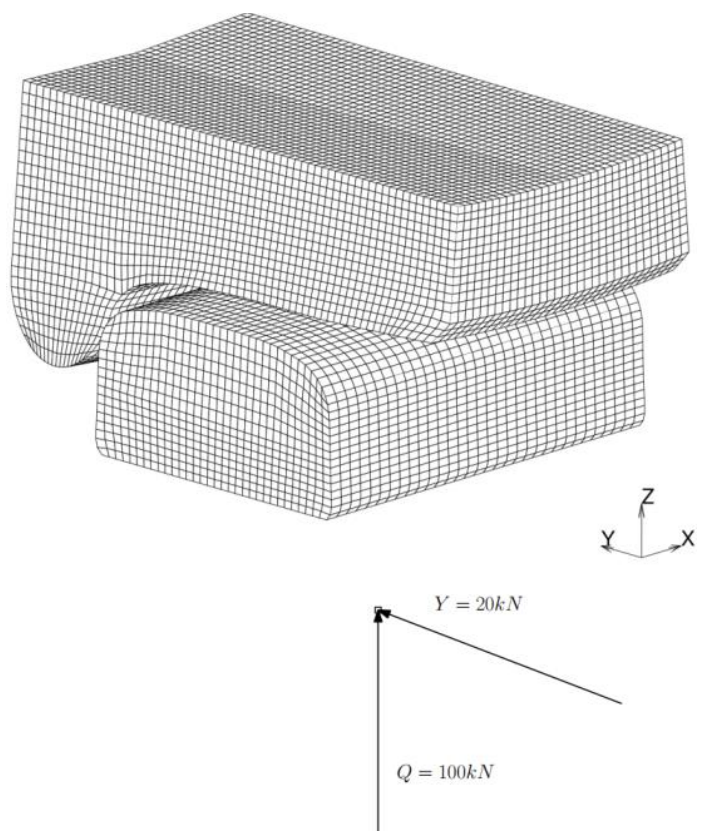

Figure 2. Sub model of the wheel and rail with $\mathrm{Q}=100 \mathrm{kN}$ and $\mathrm{Y}=20 \mathrm{kN}$

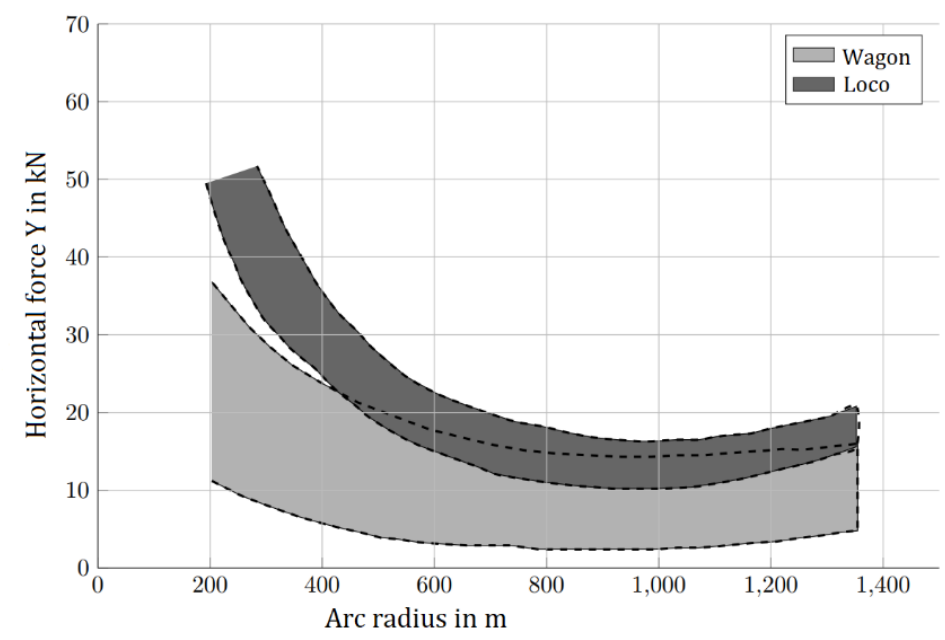

Figure 3. Horizontal force $\mathrm{Y}$ according to arc radius 
To realize a sensitive contact simulation, an area of elements with an edge length of about $0.2 \mathrm{~mm}$ is embedded in this sub model for the wheel and rail. Figure 4 shows a cut through the railhead with the elements of $3 \mathrm{~mm}$ and $0.2 \mathrm{~mm}$ of edge length. A detailed view of the elements with an edge length of $0.2 \mathrm{~mm}$ is shown in Figure 5 . The assigned material is defined as elastic-plastic with a stress-strain curve as shown in Figure 6 which corresponds to a rail steel grade $\mathrm{R} 260$.

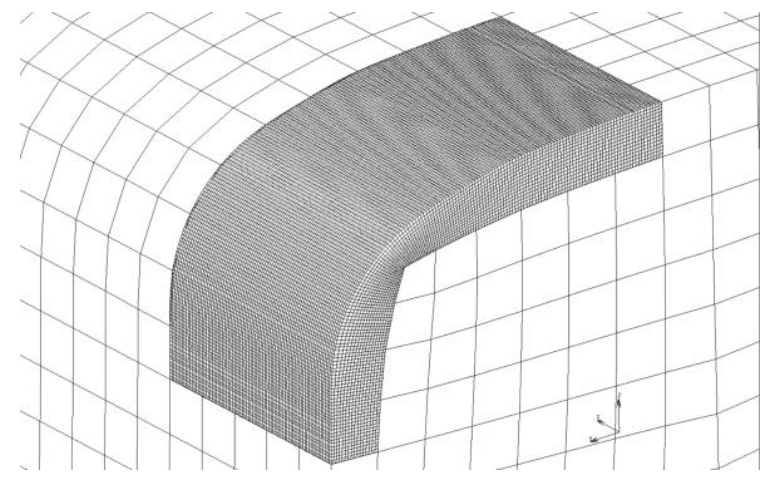

Figure 4. Cut through the sub model of the railhead with fine meshing at the area of contact

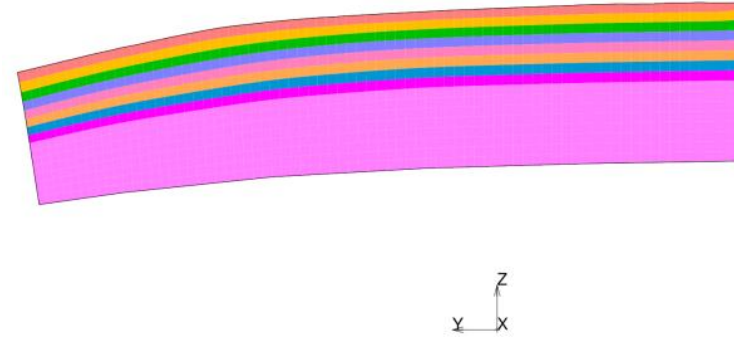

Figure 5. Detailed view of the element layers at the area of contact

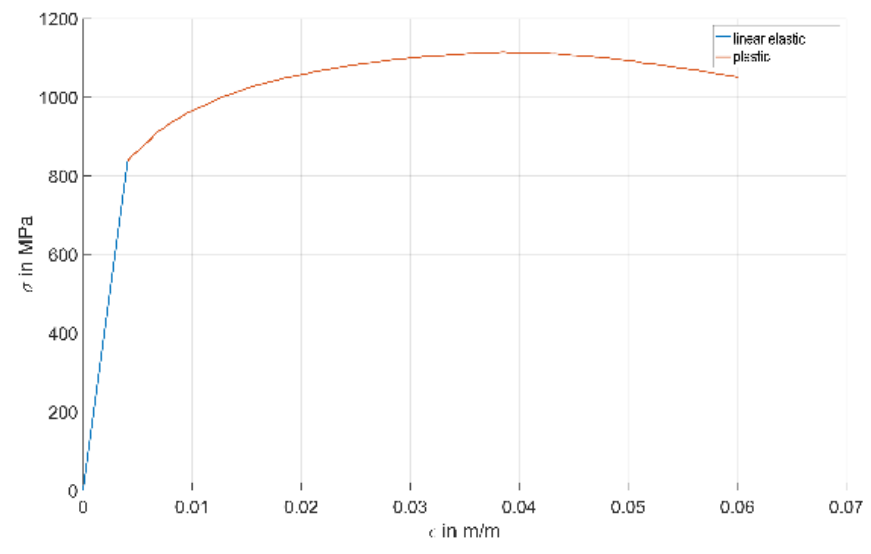

Figure 6. Stress strain curve of the material [9]

\subsection{Contact simulation between wheel and rail}

The contact simulation is a combination of two solution methods of the simulation software. The first solution method is a static contact, while the second method is called steady state rolling which can simulate the rolling motion between the wheel and rail. For the steady state rolling, the rotation speed of the wheel and the velocity of the train must be entered. In this case, a train speed of $2.8 \mathrm{~m} / \mathrm{s}$ is defined with a rotation speed of the wheel of 1 rotation per second. To consider the transmission-slip s, a friction coefficient with dependency on relative velocity between the wheel and rail was used (see Figure 7). The highest friction coefficient is defined with $\mu=0.33$, while the friction at higher relative velocity which is equitable to higher transmission slip is defined with $\mu=0.2$. Higher friction may lead to higher stresses near the surface. The result of the simulation is the stress distribution at the wheel and the rail (see Figure 8) in which the legend has a range of 0 to $700 \mathrm{MPa}$. 


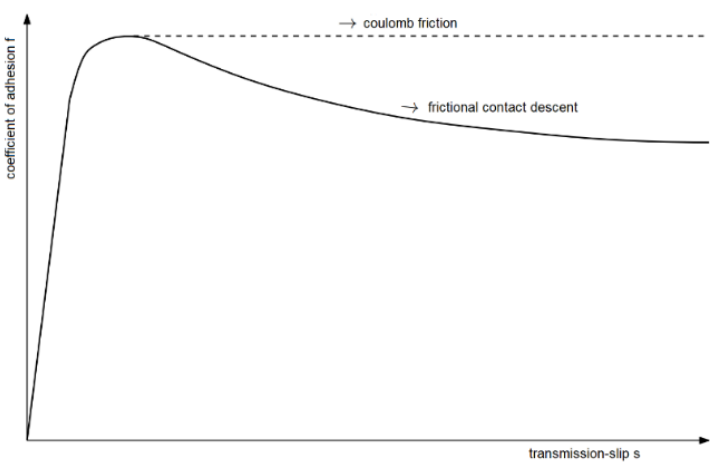

Figure 7. Course of the curve of coefficient at adhesion and transmission-slip [10, p. 343]

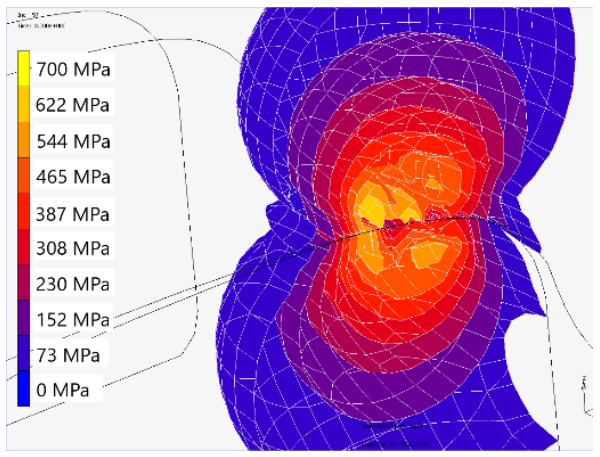

Figure 8. Cut through wheel and rail during contact shows the von Mises stress as 3D iso surfaces

\subsection{Fatigue calculation}

For fatigue calculation, material data are necessary, e.g., in the form of a SN-curve, including the stress amplitudes with the stress ratio as well as the number of load cycles. As published by Miner in [11], the cumulative damage under repeated loads can be calculated according to equation 1. It is defined as the sum of all sub-total damage, calculated with the endure load-cycles $n$ proportional to the bearable load-cycles $N$. The number of loadcycles $N$ depends on material, stress amplitude and type of stress (normal stress, shear stress, equivalent stress, ...). According to [12], a damage sum of $\mathrm{D}=1$ is considered critical and can lead to component failure. In the present example, this limit is adopted. Component tests on rails can result in more precise limits.

The characteristic values for the SN-curve (slope and permissible amplitude stress at 2 million load cycles) are converted from the static tensile test data using the Uniform Material Law (UML) [13]. The stresses are taken directly from the results of the solver and assumed to be a purely threshold load. The number of load cycles in which the damage is to be extrapolated is specified in advance to a number of 200,000.

To perform a damage calculation in the simulation software, a user subroutine is used. This script, written in FORTRAN, accesses the current results of the solver, processes them, and saves the data as an additional result.

The data of the SN-curve and the number of load cycles required for the calculation are assigned to the material as general state variables at the pre-processing. The user subroutine (User Sub PLOTV [14]) now accesses these general state variables as well as the von Mises stress determined in each calculation step and performs a linear damage accumulation at each integration point. At the post-processing, this damage can be displayed as a result.

$$
\sum \frac{n}{N}=1
$$

\subsection{RESULTS AND DISCUSSION}

The results in Figure 9 and 10 show a distribution of damage both on the rail surface but especially in the volume of the material. Figure 9 shows the volume with a damage D>1. Partly, the damage occurs on the surface of the rail. Due to the high von-Mises stress under the surface, the calculated damage gains the maximum in the volume. To achieve a better impression on the distribution of the damage, a cross section in the $\mathrm{x}-\mathrm{z}$ plane is shown in Figure 10. The result is consistent with the occurrence of damage on rails that occurs partly on the surface, e.g., head checks [15], but also damage that first occurs under the surface and only grows outwards over time [10], [16-20]. To achieve sound knowledge, more investigations are necessary. 


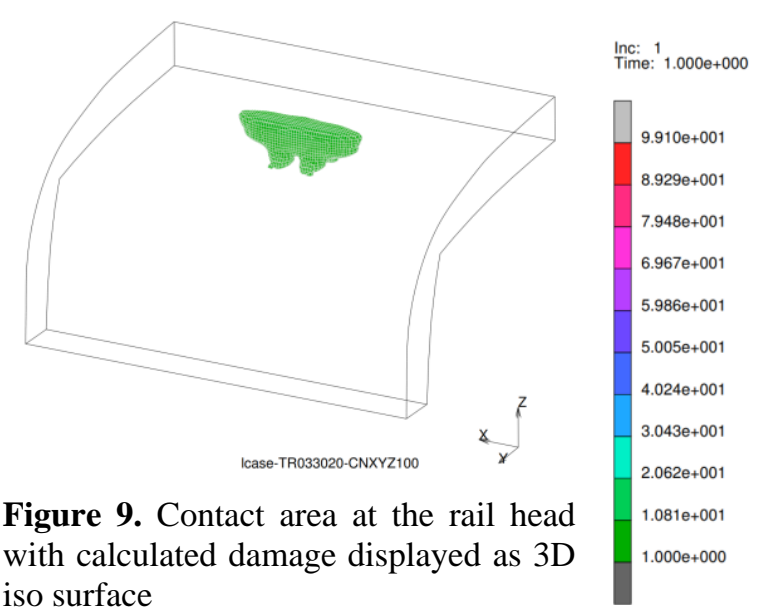

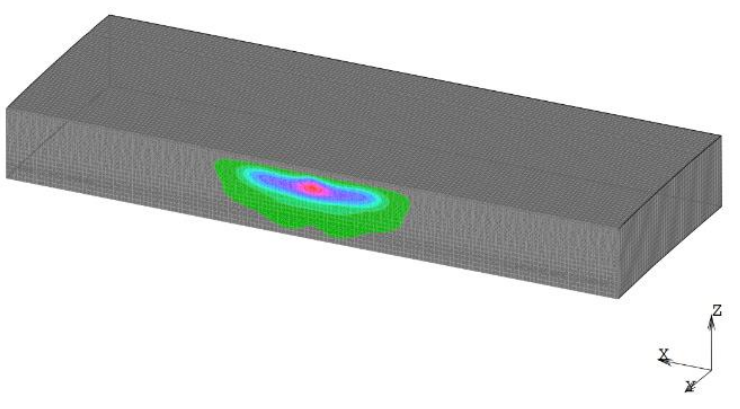

Figure 10. Cut through the contact area at the rail head with calculated damage

The present procedure is intended to show the principle access to a damage calculation within the finite element software used. The first advantage is the direct use of all results from the solver and the representation in the postprocessing. The additional benefit is the calculation of the damage in the whole volume of the component at once, especially when it is known from experience that cracks can occur under the component surface.

However, in the present case, the interpretation and the statement about the absolute amount of damage must be taken with caution. The use of von Mises stress is based on the simple application, knowing that the result can deviate far from reality. To achieve more accurate estimations, further investigations must be carried out regarding the material and its behaviour under a multiaxial stress condition. The constant over rolling in daily use can lead to a de- or hardening of the material. These are only two of several influences that must be considered in the calculation. Only when these and further effects have been clarified, a practical application of the fatigue calculation in the volume can be used for a proper calculation of the local damage.

\subsection{CONCLUSION}

The aim of this paper is achieved which is to present an application to use a built-in fatigue calculation and damage evaluation in the same software. As shown, the methodology is able to assess possible areas of damage under the surface.

For further studies, the multiaxial stress situation could be considered in applying the critical plane approach [21] or other damage models [22]. Moreover, an experimental proof of the local stresses under real conditions and loadings at the rail would improve the finite element simulation. Both inputs could advance the forecast of fatigue damage under rolling contact conditions.

\section{REFERENCES}

[1] B. Hafner, Streckenklasse. [Online]. Available: https://blog.railcargo.com/de/artikel/eisenbahn-einfacherklaert-interoperabilitaet/eisenbahn-einfach-erklaert-streckenklasse

[2] E. Magel, P. Mutton, A. Ekberg, and A. Kapoor, "Rolling contact fatigue, wear and broken rail derailments," Wear, 366-367, pp. 249-257, 2016, doi: 10.1016/j.wear.2016.06.009.

[3] C. Jessop, J. Ahlström, L. Hammar, S. Fæster, and H. K. Danielsen, "3D characterization of rolling contact fatigue crack networks," Wear, 366-367, pp. 392-400, 2016, doi: 10.1016/j.wear.2016.06.027.

[4] S. Gu, X. Yang, S. Zhou, S. Lian, and Y. Zhou, "An innovative contact partition model for wheel/rail normal contact," Wear, 366-367, pp. 38-48, 2016, doi: 10.1016/j.wear.2016.07.001.

[5] I. Kaiser, "Hochdetaillierte Modellierung der Fahrzeug-Fahrweg-Wechselwirkung,"

[6] M. Toumi, H. Chollet, and H. Yin, "Finite element analysis of the frictional wheel-rail rolling contact using explicit and implicit methods," Wear, 366-367, pp. 157-166, 2016, doi: 10.1016/j.wear.2016.06.008.

[7] L. Reis, B. Li, and M. de Freitas, "A multiaxial fatigue approach to Rolling Contact Fatigue in railways," International Journal of Fatigue, vol. 67, pp. 191-202, 2014, doi: 10.1016/j.ijfatigue.2014.02.001.

[8] G. Trummer, C. Marte, S. Scheriau, P. Dietmaier, C. Sommitsch, and K. Six, "Modeling wear and rolling contact fatigue: Parametric study and experimental results,” Wear, 366-367, pp. 71-77, 2016, doi: 10.1016/j.wear.2016.04.024.

[9] Technische Universität Graz, RSS-Rail System Security. [Online]. Available: https:// graz.pure.elsevier.com/de/projects/rss-rail-system-securi-rss-rail-system-security (accessed: May 27 2021). 
[10] B. Lichtberger, Handbuch Gleis: Unterbau, Oberbau, Instandhaltung, Wirtschaftlichkeit, 3rd ed. Hamburg: Eurailpress DVV Media Group, 2010.

[11] M. A. Miner, "Cumulative Damage in Fatigue," J. Appl. Mech, vol. 12, no. 3, A159-A164, 1945, doi: 10.1115/1.4009458.

[12] E. Haibach, Betriebsfestigkeit: Verfahren und Daten zur Bauteilberechnung, 3rd ed. Berlin: Springer, 2006.

[13] S. Korkmaz, "Extension of the Uniform Material Law for High Strength Steels," Master Thesis, Bauhaus University, 2008.

[14] V. Kulkarni, Marc Volume D: User Subroutines and Special Routines - 2020 FP1, 2020.

[15] D. Benoît, B. Salima, and R. Marion, "Multiscale characterization of head check initiation on rails under rolling contact fatigue: Mechanical and microstructure analysis," Wear, 366-367, pp. 383-391, 2016, doi: 10.1016/j.wear.2016.06.019.

[16] R. Lewis, U. Olofsson, J. E. Garnham, and S. Grassie, Eds., Wheel-rail interface handbook, 2009.

[17] S. Kaewunruen, M. Ishida, and S. Marich, "Dynamic Wheel-Rail Interaction Over Rail Squat Defects," Acoust Aust, vol. 43, no. 1, pp. 97-107, 2015, doi: 10.1007/s40857-014-0001-4.

[18] UIC Code 712 // Schienenfehler: Défauts de rails = Rail defects, 4th ed. Paris: UIC, 2002.

[19] W. Schoch, Rollkontaktermüdung Ein Überblick Über Ein Weltweites Phänomen. [Online]. Available: http://www.dgzfp.de/portals/eisenbahn2014/BB/3.pdf

[20] E. E. Magel, Sawley Kevin J., P. S. Sroba, and J. Kalousek, “A Practical Approach to Controlling Rolling Contact Fatigue in Ralways," in 8th International Heavy Haul Conference, pp. 447-455.

[21] Y. Wang and L. Susmel, "Critical plane approach to multiaxial variable amplitude fatigue loading," Frattura ed Integrità Strutturale, vol. 9, no. 33, pp. 345-356, 2015, doi: 10.3221/IGF-ESIS.33.38.

[22] J. LeMaitre, Ed., Handbook of materials behavior models. San Diego: Academic Press, 2001. 